\title{
XXVI. On the general existence of a newly observed and peculiar property in plants, and on its analogy to the irritability of animals
}

Henry Johnson M.D.

To cite this article: Henry Johnson M.D. (1835) XXVI. On the general existence of a newly observed and peculiar property in plants, and on its analogy to the irritability of animals, Philosophical Magazine Series 3, 6:33, 164-169, DOI: 10.1080/14786443508648561

To link to this article: http://dx.doi.org/10.1080/14786443508648561

曲 Published online: 01 Jun 2009.

Submit your article to this journal $[\pi$

Џll Article views: 2

Q View related articles $\sqsubset$ 
defined dark object on a luminous ground, and the most perfect and colourless vision of this object will be obtained in and near the common axis of the eye and the lens. Now in this case we have sensibly colourless vision, although the lens is not achromatic, and although its chromatic aberration is increased by whatever colour there may be in the eye itself. How much more, then, should vision be sensibly colourless near the axis of vision, and with the eye alone, when we consider that it is composed of substances which have a much lower dispersive power than glass!

Mr. Powell has quoted the admirable paper of Dr. MaskeJyne, in which, without referring to the physiological fact on which I have proceeded, he regards the eye as a lens, and calculates the amount of indistinctness in the image which it forms. He has shown that the calculated dispersion, which we believe to be even less than he makes it, is not incompatible with distinct vision, and he has pointed out causes which tend to diminish the injurious effects of this dispersion. But though $\mathrm{Mr}$. Powell quotes these results, he does not attempt to call them in question, or to disprove them by other calculations founded on more recent measures of dispersive power; and until this is done, great weight must be attached to the reasoning of Dr. Maskelyne.

After a careful perusal of Mr. Powell's Memoir, I have no hesitation in stating that $I$ continue to maintain the opinions which, along with others, I have published on this subject; and that I consider the non-achromatism of the eye as a fact as well established as any other fact in natural philosophy.

Belleville, January 15th, 1835.

XXVI. On the General Existence of a nervly observed and peculiar Property in Plants, and on its Analogy to the Irritability of Animals. By Henry Johnson, M.D.*

DO not know that it has ever been remarked, that, on dividing the stem of almost any herbaceous plant, a singular separation of the divided segments uniformly occurs, and that this separation continues until the stem withers and dies from the loss of its moisture.

It was in the autumn of 1827 that I first observed this fact; and from an opinion which at once occurred to me that it was connected with the motive powers of the plant, I have been induced, since that period, to pay much attention to the

* Communicated by the Author. This paper is an abstract of a Memoir read before the Ashmolean Society of Oxford. 
subject, and to perform very numerous experiments, with a view to learn its peculiar nature and effects. It will be my business in the following pages to state, as succinctly as possible, some of the results of my inquiries.

To the phænomenon above mentioned, I have hitherto applied the term divergence, under which appellation I shall here continue to speak of it. But, as the evidence which I am about to adduce has convinced me of the analogy, if not the identity, of this property with what physiologists call irritability* ${ }^{*}, 1$ shall in future venture to consider them as similar principles, and substitute the word irritability for that of divergence.

The experiments which follow will afford a sufficient illustration of the phænomena of divergence.

Exp. 1. A portion of the stem of a White Dead-Nettle (Lamium album), was divided at one extremity with a lancet, the division being carried to the length of $1 \frac{1}{2}$ inch. The segments instantly separated from each other one inch, which gradually increased to $1 \frac{2}{8}$ inch. The sketch, fig. l. will serve to show the appearances which presented themselves, $a$ a being the stem previously to, $b b$ the same after division, $c c$ the divided segments in a state of divergence.

Fig. 1.
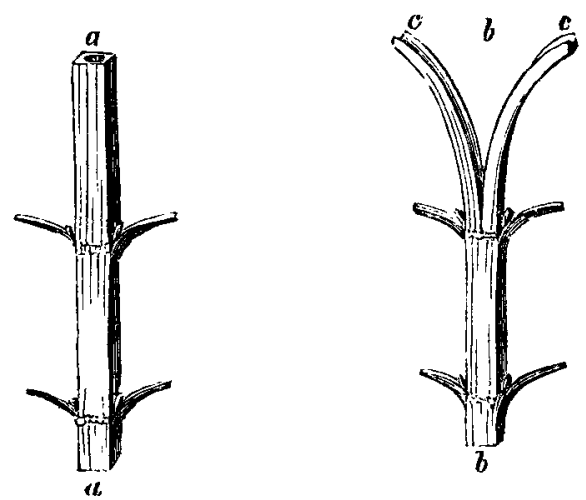

Exp. 2. A slender spray of Yellow Jessamine was divided down the middle. The two segments instantly separated from each other, and remained so when the spray was held in an inverted position; thus showing that the effect did not depend on the weakened segments bending outwards from

* See System of Physiology, by J. Bostock, M.D., vol. i. p. 160. 
their own weight. Fig. 2. $\alpha$, represents the stem in its proper, $b$ in an inverted position.

$a$

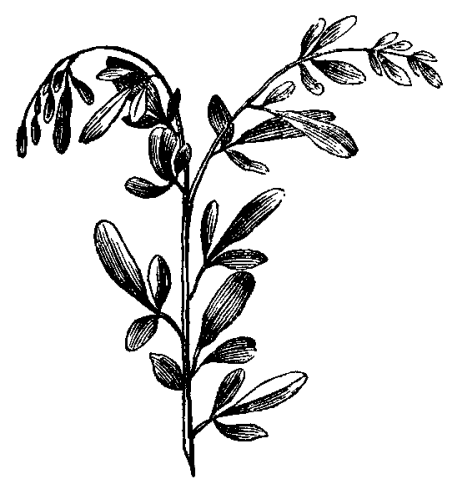

Fig. 2. $\quad b$

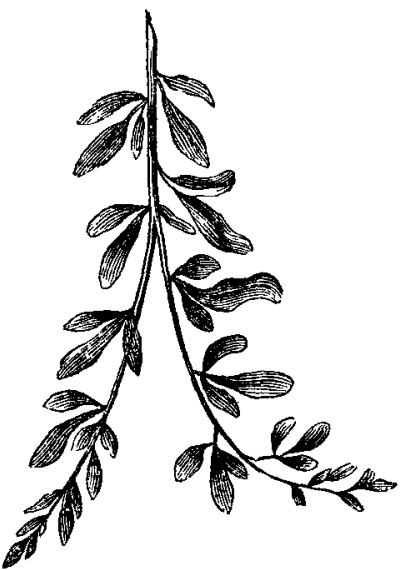

By experiments similar to the preceding, I have detected this property in above seventy different genera of plants, a table of which is now beside me, but which would occupy too much room to be here inserted.

Divergence being thus proved to exist very generally in plants, let us, in the next place, endeavour to learn something of its nature and cause.

After carefully considering all the observed facts, I am led to conclude, that they must depend, either on physical elasticity, or on that vital contractile power which is called irritability. No other known principle suggests itself to which I can reasonably ascribe them. The following facts prove, I think, very clearly that the phænomena of divergence are not due to elasticity.

1. The woody parts of trees, and even the rattan cane, which are certainly some of the most elastic vegetable substances, never exhibit divergence on division*.

2. The stems of many plants which in their recent and growing state are divergent on division, lose this property when they become dead and dried, although they are in the latter case much more elastic than before. For example, the stem of the Common Teasel (Dipsacus fullonum), which is strongly divergent in its recent green state, loses this property

[* A botanical friend suggests the inquiry whether Dr. Johnson has ever tried the effect of division on Dirca palustris, or any plant of the natural order Thymelcee?-EDrT.] 
entirely when it has become dry and reathered (as geologists would say) by exposure in our hedges through the winter. But, in the latter case, it is most certainly much more elastic than when alive and growing.

3. Lastly, Poisons destroy the power of divergence, which they would not do if it were dependent on a mere physical cause such as elasticity. This fact I state on the authority of very numerous experiments, which it seems needless to relate circumstantially.

I infer, then, from the preceding facts and arguments, that elasticity is not the cause of divergence. I proceed, in the next place, to state the experiments and observations which lead me to conclude that it is a vital property.

1. It is most active in those parts of plants which exhibit other vital properties and functions in the greatest perfection. For instance, whilst, as I have stated above, it does not exist in dead wood, and ceases as a plant loses its moisture, it is found in stems, and flower- and leaf-stalks when in their most vigorous and healthy state.

2. If the opinion, that this property is of a vital nature, were correct, $J$ thought it would be destroyed by poisons, and this I find to be the case whether a plant be supplied with a poisonous liquid instead of water, or a divergent stem totally immersed in such a liquor. I shall give the following experiments in proof of this.

Exp. 3. A stem of Bryony (Bryonia dioica) was placed in a solution of arsenite of potash *. In two days it became so flaccid that the head and tendrils hung downwards. They were not discoloured, and but little shrivelled. The divergent power was completely destroyed.

Exp. 4. I confined two stems of a Red Dead-Nettle ( $L a-$ mium purpureum) in an inverted jar filled with sulphuretted hydrogen. In two days one of the stems was so perfectly flaccid as to be incapable of holding up its head. They were not withered, and the blossoms only looked a little paler. Every part of the stems which was exposed to the influence of the gas had completely lost its divergent power.

3. The following experiments show that the divergent power is capable of being excited or increased by stimulants.

Many poisons, whose ultimate effect is to destroy this property, do at first increase it. This has occurred with laurelwater, dilute nitric acid, brandy, oil of turpentine, hot water, and a mixture of æether with sal volatile. Cold water, also, so augments the divergence of the segments of a divided stem,

* Made by boiling together in $1 \frac{3}{3}$ of water 8 grains of white arsenic and the same quantity of subcarbonate of potash. 
that they become curled up in circles or spiral coils. Every one has seen an instance of this sort in the case of common celery when dressed for the table. More remarkable proofs of stimulation are, however, afforded in the following experiments.

Exp. 5. Several pieces of the stems of different plants were divided, and, in a state of divergence, were immersed in hot water. The divergence was at first increased in all, but in a few minutes they entirely collapsed; and their divergence was totally destroyed.

Exp. 6. I procured a young and vigorous flower-stalk of the Common Dandelion (Leontodon Taraxacum) which curved considerably to the left side, fig. 3. Several notches $(a, a, a, a$, $)$ were then made in the concave side, extending towards the axis of the flower-stalk. The latter instantly became erect! and, on cautiously applying a red-hot poker near to the entire side, the fibres in the latter appeared to be contracted, and the stem was now drawn towards that side (i.e. to $h$ ), the right; namely, the opposite to that to which it inclined at first.

Fig. 3.

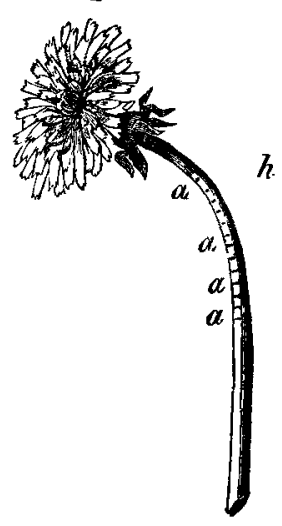

Having concluded from the arguments above stated (pp. 166 and 167,) that divergence is the result of a living or vital action, we learn, from Experiments 3 and 4, that it is entirely destroyed by poisons, which is what might be expected to take place if this supposition were well founded. If to this any one should object, that even physical properties such as elasticity, that of a quill for example, may be destroyed by poisonous liquids which have also chemical effects; I answer, that the objection has been already foreseen, and is in my opinion completely refuted, by the fact, that similar effects are produced by laurel-water, and even by sulphuretted hydrogen gas, which have little chemical activity.

There can be no doubt, therefore, that poisonous liquids act on plants as vital agents in the same way as that in which they would act on the living system of animals*. When it is proved, also, by Experiments 5 and 6, that stimulants act on parts endowed with this property, just as they would do on

* It appears from Dr. Christison's Work on Poisons, that it occasionally happens when these agents are taken into the stomach that the contractility of the muscles is destroyed. 
Mr.Clarke on a new Phanomenon in Magneto-Electricity. 169

the contractile organs of animals, as the heart and other muscles, it seems to me to be a legitimate inference from all which has been said, that divergence is a vital action, and in every sense analogous to the contractility or irritability of the animal system.

In a future communication I shall endeavour to extend this analogy, by showing that the motions of plants may be traced to this same property, as those of animals are to irritability*.

Shrewsbury, Oct. 6, 1834.

XXVII. On a nero Phanomenon in Magneto-Electricity. By Mr. Edward M. Clarke.

To the Editors of the Philosophical Magazine and Journal. Gentlemen,

HAVING for some time past been engaged in the manufacture of the new magnetic electrical machines, in their completion and in the subsequent trials of their action I have observed a phænomenon which I have not anywhere seen an account of. I shall describe the effect as briefly as I can : in order to do this I have furnished a diagram of part of the machine.

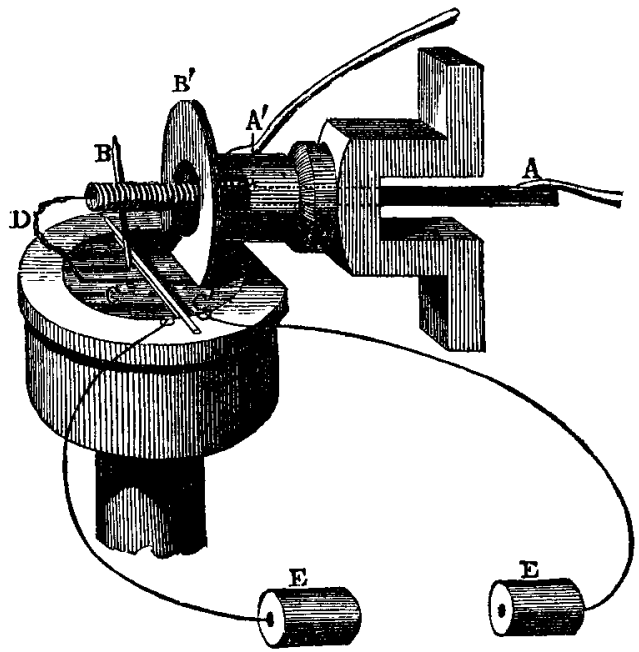

[* We are indebted to a medical friend for the remark, that the phænomenon described by Dr. Johnson most closely resembles the contraction of the ligamentum nucha, by which the head of animals is retracted after death, and which Bichat attributes to vital contractility, which he regards as a distinct property.-EDrT.]

Third Series. Vol. 6. No. 33. March 1835. 